\title{
Pragmatism and Human Values in Some Short Stories of Chitra Banerjee Divakaruni
}

\author{
Dr. Parmendra Kumar Mishra
}

Assistant Professor (Guest), Department of Commerce and Business Administration, L. N. Mithila University, Darbhanga, Bihar, India

\begin{abstract}
Chitra Banarjee Divakaruni for her exceptional literary acumen has got several distinctions and awards. In 1989, she was given Memorial Award from Barbara Deming Foundation. In 1990, Santa Clara Country Arts Council honoured her for writing award. In 1993, she was honoured with writing award from Gerbode Foundation. She also got honor of receiving PEN Oakland Josephine Miles Prize for fiction. For the book Hearing Yuvacity she was given Ginsberg Poetry Award and push card Prize. She got American Book Award for her brilliant collection of short stories entitled Arranged Marriage. Before Columbus Foundation in 1996, The Mistress of Spices was nominated as the best book of 1997 by Lost Angles Times and best paper back of 1998 by Seattle Times. The literary career of Chitra Banerjee Divakaruni begins with the publication of her debut short collection Arranged Marriage (1995). The realist discourse of cultural conflict in the multilingual society forms a central motive in her writing.
\end{abstract}

Keywords-discourse, culture, multilingual, society, pragmatics.

"The Intelligence of Wild Things" explains the phenomenon of how the shift of geography creates some irresolvable barriers, however Divakaruni endeavors to address the structural realities of all binaries and tries to establish balance between past and present, native and alien, pragmatism and human values and the temporal and timeless. Towards the end of the story, Divakaruni condemns the narrator and she records, "That is the trouble with our Indian families, always worrying too much. Is it good for your brother to be on his own for a while. He is probably having a great time at the university. For all you know, he has half a dozen girlfriends and would much rather you did not keep tabs on him."(46). Thus the story passes through the conduit of emotional tempest where pathos and empathy dominate. The story also suggests that it is possible to reconcile the hiatus between cultures but is extremely difficult to resist the burden of emotion that is integral to human existence as it has been theorized by Arthur Danto's Narration and Knowledge (1985) 1. Similarly personal relationship also becomes the main motif of "The Lives of Strangers" which is explained through the story of a Pilgrim Party that moves from Calcutta to the holy caves of Amarnath. Leela the main narrator of the story expounds the reality of the dominance of religion upon human Indian consciousness. Divakaruni through the character of Leela registers the excitement and sensation of the Pilgrims. She records, "Their eyes sparkle with zeal as they discuss how remote the shrine is. How they will have to talk across treacherous glaciers for three whole days to reach it. Leela wonders if this is true lure of travel, the hope of transformed self. Will her own journey, begun when she left America a month ago, bring her this coveted change."(55). Further the story "Love of a Good Man" also addresses the question of personal sensitivity and conflict. The plot of the story encapsulates the action and the narrative of the mother and the father in order to unfold the thematics of emotional crises and the texture of emotional crises has aptly been delineated by Jain, Jasbir Jain's Writers of Indian Diaspora(1998) ${ }^{2}$.

The story "Only the Body Knows" provides the reader with a graphic account of psychological and pathetic sensation of a young married lady who intends to come out the trauma of immigration. Aparna who is the protagonist of the story is a young married lady who is found to be utterly busy in visiting doctors, taking iron pills and reading some books on baby care. Similarly the dilemma of personal relationship is also the central theme of the story "Forgotten Children" in which the narrator is a young girl who faces the trauma of negligence of parents. She experiences insecurity, uncertainty and 
lack of belongingness which is explicitly clear when she says, "But we saw it in our mother's face, the way she sometimes broke off a sentence and stared out of the window, forgetting that I and my brother were waiting" (146). It is demonstrated that the narrator feels herself isolated rather an integral part of her family. The story of "Glooming Season of Cacti" is an account of a girl who plans to visit California to see her brother. Before she emigrates from India she dreams of all beautiful geographical contours of California. She says, "I loved it how could I resist I wanted to climb to the top of the highest dome. I wanted to be transformed to the bone."(168). Finally, when the volume comes to "The Unknown Errors of Our Lives" the writer turns towards the complex texture of human relationship. She does not provide the reader with psychological crisis in human relationship but she also underlines different lacunas and gaps which may fissure the human relationship in social and cultural hemisphere as has been adumbrated by John Mc Leod's Literature of Indian Diaspora $(2000)^{\mathbf{3}}$. The ultimate story entitled "The Names of Stars in Bengali" involves the poetics of exile, obscurity between mother and daughter relationship, nostalgia for the childhood memories and the clash of values of East and West. In a nutshell the story sums up all major arguments that Divakaruni has attempted to establish. Beena Agrawal in her Chitra Banerjee Divakaruni: A New Voice in Indian English Fiction (2016) reinstates:

The experiments with the dimension, variety and intensity within the limited canvas of short story impart a distinction and innovative direction to the sensibility of Divakaruni. Liveliness, twilight of gloom and joy, depth of sentiments and deconstruction of invisible spaces of human consciousness constitute the texture of her writings. The light of the prism of the short stories of Divakaruni collected in the volume The Unknown Errors of Our Lives of her reflects and represent the domain of her Diasporic realities.
Her over sensitivity for the emotional affinities in personal relationship at the diverse levels of human experiences make her stories a thing enduring popularity that is beyond the constrains of time, place and cultural constrains. The echoes of human sentiments give a window to the sublimity and the distinction to the art of Divakaruni ${ }^{4}$.

Apart from her fictional works, Divakaruni is also known for her poetic composition. The corpus of her poetic composition is a rich testimony of her profound thoughtfulness, richness of imagination, deep emotional appeal and seriousness of purpose. Her celebrated poetic collections are Dark Live the River (1987), The Reason for Nasturtium (1990), Black Candle: Poems about Women from India, Pakistan, Bangladesh (1991), and The Leaving Yuba City(1997). These collections echo the voices of Indian immigrants settled in America. Divakaruni has attempted to paint the curiosity and sensibility of children. She has written Neela, Victory Songs (2002) where the sketches have focused on the adventures of a twelve year old girl whose father was involved in the struggle of Indian war of Independence. Similarly, The Couch Bearer (2003) presents a fantasy in which twelve year old Anand returns a magical Couch shell to the distant Himalayans from which it had come. In context of The Couch Bearer, the quest adventure has an exotic flavour, magical background from traditional Tales and deliciously detailed description of Indian food.

Like Bharati Mukharjee, Chitra Banerjee through her novels constructs the world of immigrant's experiences and represents the plight of Indian immigrant women. The emotional identification and affirmation of self-anguish through their conflicts; provide a rare authenticity to her narrative presentations. With the nostalgia of these women immigrants, she represents her own emotional affinity with Indian culture and Indian traditions. She makes a confession that without having an insight in the inner consciousness of Indian women, her fictional art world has been weak and insignificant. She mentions:

So much of my writing was a response to imagination and being far away from my culture that really made me want to write about India. If I did become a writer in India, surely I would have written about other things, I do work with Indian women. I have several students right now at the university of Houston who are Indian or Indian American or South Asian. (Interview; Ranjan)

In the galaxy of immigrants' literature, Divakaruni breaks the traditional matrix of 'home and homelessness' and 
constructs varied narrative patterns to provide ample spaces to her immigrant characters to reveal their suppressed sensibility for their homeland. Besides of the nostalgia of the characters, she encourages ethnic arts, performances, ethics and poetic realization of native sensibility. She has a realization of paradigms and commitments of her narrative art. Locating her position in the realm of Indian Diasporic writers, she admits:

Each one of us has our own concerns, style and subject matter. Some of mine are immigrant issues, women's roles and an interest in folk tales and magic. I have also become very interested in writing for children. (Interview: Deslit Daily)

Divakaruni's fictional world is made out of the fine fusion of fantasy and the harsh reality of life. She constructs the idiom of exile beyond the romantic notion of nostalgia and promotes a rational emotional vision to construct the inner world of the immigrants. She makes a mention of her vision, "I'm not sure I can claim to be a voice of reason. I am often swayed by my passion, things I believe in strongly. And I think it would be a generalization to say that our society is dominated by shrill rhetoric but there are many sane and wise voices out there." (Interview: Shea Mike). It suggests that Divakaruni in spite of her fascination for magic and fantasy is a 'committed' writer and never deviates from the track of the 'seriousness' of purpose. Her agenda is evident because in her writings, she presents the message of cross- cultural understanding beyond the ivory towers of academia. She defines her own positions, "I am a listener, a facilitator, connectors to people, to me, and the art of dissolving boundaries is what living is all about." (Interview: Softky Elizabeth). As a writer she fulfils a significant role, the role of the 'connector' of cultures. She writes with the assumption that women as immigrants, have a better sense of cultural identity and they can more successfully work for the assimilation of cultures. Deviating from depressing cultural bouts, she records the incidents and the consequences of the horrors of violence against women crossing cultural boundaries. The idea of national consciousness, realization of the warmth of the mechanism of personal relationship, innate bonding with geography and culture, inheriting the heritage of ethnic arts, have been the prime issues integrated in the Diasporic consciousness presented by Divakaruni in her writings.

Hence, one can say that the experiments with the dimension, variety and intensity within the limited canvas of short story impart a distinction and innovative direction to the sensibility of Divakaruni. Liveliness, twilight of gloom and joy, depth of sentiments and deconstruction of invisible spaces of human consciousness constitute the ISSN: 2456-7620 texture of her writings. The light of the prism of the short stories of Divakaruni collected in the volume The Unknown Errors of Our Lives of her reflects and represent the domain of her Diasporic realities. Her over sensitivity for the emotional affinities in personal relationship at the diverse levels of human experiences make her stories a thing enduring popularity that is beyond the constrains of time, place and cultural constrains

\section{REFERENCES}

[1] Danto, Arthur C. Narration and Knowledge. New York: Columbia University Press, 1985

[2] Jain, Jasbir. Writers of Indian Diaspora, Jaipur: Rawat Publications, 1998

[3] Mc, Leod. Literature of Indian Diaspora, New Delhi: Sterling Publishers Pvt. Ltd., 2000

[4] Agrawal, Beena.Chitra Banerjee Divakaruni: A New Voice in Indian English Fiction.New Delhi: Atlantic Publishers and Distributers, PP- 204.2016. . 